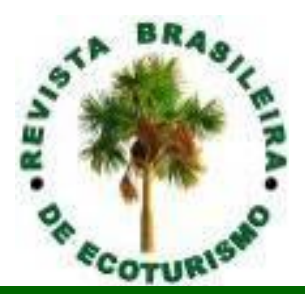

\title{
Experimentando o conhecimento: o Turismo Pedagógico como ferramenta para o Ensino Profissional
}

\section{Experiencing the knowledge: educational tourism as a tool for teaching and learning}

Flavia Oliveira da Silva Louzeiro

RESUMO: O turismo enquanto vetor do desenvolvimento de sociedades requer um cuidado em relação à qualidade da experiência e da profissionalização, nesse sentido o turismo pedagógico pode contribuir de modo contundente à formação de profissionais com olhar diferenciado para a responsabilidade social. $\mathrm{O}$ Grupo de Pesquisa em Patrimônio Cultural UFMA, vinculado ao Departamento de Turismo e Hotelaria, desenvolve entre suas linhas de atuação trabalhos que buscam apropriar-se das demandas do turismo na região Nordeste. Partindo das temáticas do turismo pedagógico, da educação patrimonial e da sustentabilidade, as autoras, enquanto participantes desse grupo, desenvolveram uma pesquisa oriunda de um trabalho prático-pedagógico realizada no estado de Pernambuco com futuros guias de turismo do estado do Piauí, buscando analisar os efeitos decorrentes da sua participação em atividades práticas no âmbito do turismo, com fins a otimizar a compreensão, o entendimento e a formação desses futuros profissionais no que tange à questões sensíveis tanto ao ambiente, quanto ao ser humano. A metodologia utilizada foi no sentido de identificar as práticas do turismo pedagógico na eficácia do aprendizado e na absorção do conhecimento produzido em sala de aula, para tanto utilizou-se FREINET, AB'SABER, SANTOS, PERINOTTO como norteadores dessa elucidação. Foi possível perceber que a partir da utilização de ferramentas educacionais, mediantes a apropriação previa do conhecimento por parte dos alunos e a experimentação in loco da atividade turística, a importância do deslocamento sócio espacial para a ampliação de entendimentos necessários na formação de profissionais mais conscientes do seu lugar enquanto agente da transformação.

PALAVRAS-CHAVE: Turismo Pedagógico; Educação Patrimonial; Sustentabilidade. 


\section{ABSTRACT}

Tourism as a vector of corporate development requires careful about the quality of the experience and professionalism in this regard, educational tourism can contribute powerfully to the formation of professionals with a different aspect of social responsibility. The Research Group on Cultural Heritage - UFMA, linked to the Ministry of Tourism and Hospitality, develops among its lines of action studies that attempt to hijack the demands of tourism in the Northeast. Based on the issues of educational tourism, heritage education and sustainability, the authors and participants of this group developed a search derived from a job practical pedagogical conducted in the state of Pernambuco with the future state tour guides of Piauí, trying to analyze the effects of their participation in practical activities in the field of tourism, in order to optimize understanding, understanding and training of these future professionals regarding sensitive issues for both the medium environment, such as humans. The methodology used was to identify pedagogical practices tourism in the effectiveness of learning and absorbing knowledge acquired in the classroom, therefore FREINET, AB'SABER, SANTOS, PERINOTTO was used as guide this clarification. It was observed that from the use of educational tools, through the knowledge appropriation provided by students and experimentation in place of tourist activity, the importance of socio-spatial change to the expansion of knowledge needed in training the more aware of their place while processing agent professionals.

KEYWORDS: Educational Tourism; Heritage Education; Sustainability.

\section{Introdução}

A iniciativa das pesquisadoras, ao produzir este artigo, se deu, a princípio, após iniciar a participação nas discussões do Grupo de Pesquisa em Patrimônio e Cultura, da Universidade Federal do Maranhão, onde com discussões acerca da postura dos povos diante de sua percepção sobre o meio ambiente onde vivem, seus bens materiais e imateriais, discute-se 0 patrimônio como bem a ser preservado e como locus de aprendizagem.

Este estudo faz parte de um anseio maior em pesquisar e identificar as diversas possibilidades cognitivas, sociais e ambientais que o turismo pedagógico pode desenvolver em grupos de estudos que o adotem, bem como em localidades ou espaços que estejam preparados para atendê-lo.

A pesquisa inicia-se nas dependências do Instituto Federal de Educação, Ciência e Tecnologia do Piauí, Campus São Raimundo Nonato, cidade inserida nas redondezas do Parque Nacional Serra da Capivara, um dos locais mais citados internacionalmente por seus achados arqueológicos. A escolha pela cidade supracitada deveu-se à sua localização geográfica que facilitava o acesso ao ambiente da pesquisa. Faz-se importante citar que uma das pesquisadoras possui atividades profissionais na região, além do contato direto com o público estudado. Deste modo, a convivência permitiu mesmo que de modo subjetivo, perceber a apatia dos alunos às visitas efetuadas nas dependências do parque. 
O cerne da questão levantada esta em uma não apropriação do parque por aqueles que lhes são mais próximo e, portanto, seguindo a ordem natural dos acontecimentos, deveria lhe ter mais apreço. O alunado do curso Técnico em Guia de Turismo, que compreende alunos matriculados no Ensino Médio e alunos que já concluíram a educação básica em outras instituições, desconhecia a importância do parque para a região, além do que muitos nunca haviam visitado as dependências desse ponto turístico, e os que já haviam visitado não conseguiam descrever o conhecimento adquirido durante a visita e nem percebê-lo como equipamento turístico gerador de conhecimento, e fonte de renda.

Percebe-se então que os objetivos cognitivos desejados nesse tipo de experiência não estavam sendo alcançados. Através de relatórios produzidos pelos alunos, é identificada a lacuna entre a visita técnica e a apreensão do conhecimento, levando-nos a propor a sistematização através da construção coletiva e participativa de um processo de roteirização das visitas técnicas previstas, oportunizando aos discentes o papel de sujeitos construtores do seu próprio roteiro de conhecimento, com o apoio de seus professores.

No processo de aprendizagem de conteúdos práticos há necessidade de interligar variáveis de cunho teórico e prático então, metodologicamente, para o turismo pedagógico, especificamente voltados para guias de turismo a construção de um roteiro de aprendizagem, desde a sala de aula, mostrouse indispensável para obtenção das competências desejadas.

No trato dessas questões não há como falar de turismo pedagógico, sem que antes se especifique o termo turismo, construído pela possibilidade de deslocamento do sujeito de seu local habitual de moradia, para outros destinos, em tempo superior a 24 horas e inferior a um ano, onde o mesmo tenha motivação para a realização deste deslocamento, seja lazer, negócios, estudos, ou outros.

Especialistas da área do turismo definem essa atividade como um dos mais importantes instrumentos de geração de emprego e renda, em todo o mundo, sendo o segmento capaz de alavancar a economia, além de contribuir significativamente para a preservação do patrimônio natural e cultural, uma vez que esses são matérias-primas para a existência do fenômeno turístico.

O Turismo é um fenômeno social, complexo e diversificado (Andrade, 2004), uma vez que, hoje, já se concebe o turismo não só atrelado à ideia de atividade de lazer como o senso comum retrata, sua abrangência permite novas formas de analisar o fenômeno, mobilizar pessoas pelos mais variados motivos para os mais diversos destinos turísticos. Passa a ser estudado cientificamente após a Segunda Guerra Mundial, quando o movimento turístico se mostra como força econômica. As viagens de estudo ocorrem desde o século XVII, inicialmente praticadas por jovens aristocratas ingleses às principais cidades europeias, à época, chamadas de Grand Tour. Hoje denominado como turismo pedagógico, ou turismo educativo, a atividade vem sendo apontada como importante mecanismo facilitador do processo ensino-aprendizagem. 
Com relação ao turismo pedagógico, especificamente, Rubim (2010) afirma que:

O Turismo Pedagógico é a modalidade que se adequa à proposta de aproximar teoria e prática por constituir-se em sua essência por viagens ou excursões organizadas de estudo do meio com finalidade de transportar o conhecimento teórico, aprendido em sala para a realidade, enquanto oportuniza momentos de socialização e descontração.

O turismo pedagógico representa a oportunidade de explorar a relação homem-espaço, nas mais variadas perspectivas de análise do conhecimento humano (geográfico, físico, biológico, ecológico, social, etc.) de forma interativa, divertida e multidisciplinar, emprestando o olhar crítico do turismo, em situações cotidianas de viagens técnicas. A atividade do turismo pedagógico está em crescimento e observa-se que algumas instituições de ensino estão adotando a atividade supracitada na integração de conteúdos curriculares em projetos multidisciplinares. Desta forma, a memória fotográfica dos alunos, também, é construída a partir da identidade visual dos locais visitados, de suas especificidades, formatos, arquitetura, dentre outros fatores, reforçando, assim, a necessidade por preservação.

O turismo pedagógico, também reconhecido como visita técnica, viagens de estudos ou aula-passeio, além de ser apontado como prática inovadora mostra-se instrumento frequente em várias instituições de ensino particulares e públicas.

\section{Turismo Pedagógico}

$\mathrm{Na}$ busca por teoria inicial, com o intuito de fundamentar a importância do turismo pedagógico, diversos autores foram consultados, alguns com conhecimento direcionado ao turismo e outros da área pedagógica. Desta forma, foram escolhidos e priorizados para o estudo Ansarah (2001), Aziz Ab'Saber (2001), Andrade (2004), Beni (2002), Freinet (1988) e Perinotto (2008).

Como um breve histórico sobre o turismo, reconhece-se os Grand Tours como marco inicial das viagens organizadas, entre os séculos XVI e XVII, na Inglaterra, que se encontra como um país dividido entre as religiões Protestante e Anglicana, de economia fragilizada e atrasada em seu desenvolvimento intelectual. Dessa forma, as rotinas de viagens são indicadas aos filhos dos aristocratas, recém-formados, com o intuito de que essas viagens servissem de absorção de conhecimento para os mesmos. Assim, foram instituídos os Grand Tour, viagens com duração de aproximadamente dois anos, realizadas às principais cidades dos seus países aliados, organizadas e roteirizadas previamente e sempre acompanhadas de um tutor. A intenção era que, ao retornarem, estes aristocratas trouxessem consigo, novas ideias para o crescimento do país. 
Inicialmente estuda-se Andrade (2004), por sua visão e percepção sobre 0 início das viagens de estudos pelos aristocratas ingleses, e reforçadas por Beni (2002), quando complementa o retorno da atividade, principalmente nos Estados Unidos, em escolas e universidades particulares, e também adotadas no Brasil por algumas escolas de elite.

Em seguida, o conceito adotado por Perinotto (2008), cita o turismo pedagógico como ferramenta que demonstra, na prática, a teoria observada em sala de aula e faz referência sobre essa atividade ser um segmento da atividade turística, onde escolas e agências de viagem especializadas propõem o uso de viagens e aulas de campo dentro ou fora da própria cidade aos alunos do ensino básico, acreditando que, desta forma, os estudantes assumirão o papel pesquisador e transformador da sua própria realidade.

Já para Ansarah (2001), na atividade do turismo educativo, o importante é despertar o interesse no aluno para o novo conhecimento, pelo local, pelos usos e costumes da população. Afinal, o sentido de pesquisar vem da vontade de conhecer mais a respeito de determinado assunto, transformando o aluno em sujeito crítico do conhecimento repassado em sala de aula.

Na opinião do professor Aziz Ab'Saber (2001), “o papel do professor deve ser o de incentivar os alunos a construir o conhecimento da região onde vivem, desde os limites territoriais até as características geográficas, econômicas e políticas". Essas informações servirão para que os mesmos se localizem como cidadãos e sempre sirvam de base para qualquer estudo de espaços maiores (Nova Escola, jan/fev 2001 ed. 139). Desta forma, o professor/educador quando habituado às práticas do ensino tradicional e avesso a novas experiências, priva o alunado da possibilidade de enxergar novas perspectivas sobre os assuntos repassados em sala de aula e de se perceber como o centro da construção do seu próprio conhecimento.

Para reforçar a questão do papel participativo do sujeito, estuda-se Freinet (1988), um educador pioneiro em defender a ampliação dos olhares das crianças para fora do espaço escolar. Ideia, esta, revolucionária, em momentos onde o estado aplicava sua educação em função da doutrina religiosa.

Célestin Freinet foi um dos primeiros representantes do movimento da Escola Nova e um dos primeiros educadores a pensar em uma educação além do espaço escolar. Freinet criou várias metodologias de ensino, uma delas foi a aula-passeio, conhecida também pelos nomes aulas das descobertas ou estudos de campo que consistia na criança sair da sala de aula e juntamente com o professor observar situações ao ar livre. Com esta técnica o teórico observou que as crianças agiam mais livremente ao ar livre e que elas pareciam mais desinteressadas na sala de aula. Percebe-se que, ele tinha uma preocupação de colocar as crianças em contato com a natureza, bem como construir uma escola que fomentasse cidadãos conscientes e participantes críticos de um meio social. As aulas das descobertas era uma oportunidade de vivenciar para aprender e seria muito 
mais proveitosa do que ler um livro ou assistir uma aula expositiva de determinado conteúdo previamente escolhido pelo professor.

Nesse sentido, reportamo-nos a citação de Freinet:

\begin{abstract}
A classe-passeio foi para mim a tábua da salvação. Em vez de cochilar diante de um quadro de leitura do reinício das aulas à tarde, saíamos para o campo que circundava a aldeia. Ao atravessar as ruas, parávamos para admirar o ferreiro, o marceneiro ou o tecelão, cujos movimentos metódicos e seguros nos despertavam a vontade de imitálos. Observávamos o campo nas diversas estações: no inverno, quando eram abertos grandes panos debaixo das oliveiras para receber as azeitonas que caiam; ou na primavera, quando as flores de laranjeiras desabrochadas pareciam oferecer-se à colheita (FREINET, 1988, p.27).
\end{abstract}

Sem dúvida, a educação é algo importante. Logo, ela não é "certamente a panaceia para todos os problemas sociais como desejam alguns" (GOMES; COLARES, 2012, p. 288). Mas, devemos lembrar que o papel da educação é formar lugares de consciência e superação de pedagogias tradicionais que privilegiam uma classe social e economicamente superior. A essência se resume a desconstrução de contradições, como educação pública VS privada, ensino técnico VS ensino superior, professor de ensino superior VS professor de educação básica, etc.

Entende-se que o turismo pedagógico representa a oportunidade de explorar a relação homem-espaço nas mais variadas perspectivas de análise do conhecimento humano de forma interativa, prazerosa e multidisciplinar, trazendo consigo a eminente possibilidade de preservação do patrimônio natural e cultural dos locais visitados.

\title{
Educação Profissional Integrada ao Ensino de Jovens e Adultos
}

O programa do Ministério da Educação (MEC), coordenado pela Secretaria de Educação Profissional e Tecnológica (SETEC) sobre a matéria da Educação Profissional para o Ensino de Jovens e Adultos (PROEJA), trouxe consigo desafios políticos e pedagógicos, entre eles, como construir um Currículo Integrado considerando as especificidades do público da EJA. Dessa forma, o dilema sobre o papel da escola de formar para a cidadania ou para o trabalho produtivo discute sobre uma proposta curricular na perspectiva da formação integrada no sentido de superar a dualidade trabalho manual/trabalho intelectual.

As políticas públicas de Educação Profissional (EP), formuladas a partir da Lei de Diretrizes e Bases da Educação Nacional (LDBEN), expressam o discurso da inclusão dos trabalhadores no mundo da produção econômica mediante a qualificação profissional. Nesse contexto, a reforma da Educação Profissional dos anos 90, regulamentada pelo Decreto $\mathrm{n}$. 2.208/97, estabeleceu a separação entre Ensino Médio e Ensino Técnico. 
Assim, a Educação Profissional de nível técnico passou a ter uma organização curricular própria e independente do Ensino Médio. A estrutura do currículo do Ensino Técnico ficou constituída em sistemas de módulos. Neste documento, não vamos nos ater sobre as discussões em torno dos aspectos negativos sobre esta reformulação.

A perspectiva de formação integrando os conteúdos da educação geral e da formação profissional foi reestabelecida a partir da revogação do Decreto n. 2.208/97 e, consequentemente, a aprovação do Decreto n. 5.154/04. Assim, o Decreto, construído diante de contradições e disputas teóricas e políticas envolvendo diversos setores da sociedade, trouxe a possibilidade da Educação Profissional Técnica (EPT) de nível médio se articular com o ensino médio de forma integrada. Assim, essa possibilidade se consolidou no âmbito da Rede Federal de Educação Profissional e Tecnológica com o PROEJA.

Para reafirmar estas características, descrevesse parte de citação do artigo Educação Integrada e PROEJA: diálogos possíveis, publicado na Revista Educação e Realidade v. 35, n. 1 (2010), onde após descrever os passos históricos de criação do PROEJA, diz: "Estas condições históricas propiciaram, em diversos espaços, exercitar a experiência de aproximação entre formação geral e específica e de praticar, nos limites das condições históricas, uma Educação Integrada." Ou seja, uma educação que busca o desenvolvimento integral - ou por inteiro - de todas as potencialidades humanas.

A novidade do PROEJA é a integração entre formação geral e formação profissional na modalidade EJA. As discussões sobre o Ensino Médio Integrado não são recentes, porém a promulgação do Decreto $\mathrm{n}$. 5.154/04 pode ser considerado o marco dessas discussões. O Decreto prevê que umas das formas de articulação entre a Educação Profissional Técnica de nível médio e a Educação Básica é a forma integrada. Compreendendo matrícula única onde o curso deve possuir, também, currículo único, contemplando formação geral e formação profissional unificadas.

\section{Materiais e Métodos}

É importante informar que a pesquisa foi aplicada com os 24 alunos do Curso Técnico Subsequente em Guia de Turismo em outubro de 2014, em visita técnica a Pernambuco, passando pelos municípios de Petrolina, Caruaru, Bezerros, Recife, Porto de Galinhas e Itamaracá. A visita técnica nacional é parte integrante do currículo do Curso Técnico em Guia de Turismo, com habilitação em Guia Regional Piauí e Nacional/de Excursão, e deve ser realizada ao final do módulo III, último dos módulos, e esta disciplina é denominada Operacionalização de Viagem e Condução.

O destino proposto foi escolhido devido suas características históricas, culturais e patrimoniais. Petrolina, cidade à beira do Rio São Francisco e referência em desenvolvimento econômico através do plantio irrigado de frutas e do enoturismo, Caruaru famosa por seus festejos juninos, seu mercado de confecção de roupas e o artesanato em barro, a cidade de 
Bezerros, local de moradia do artesão internacional J. Borges, Recife e Olinda, cidades patrimônio, e por fim Porto de Galinhas e Itamaracá, como ambientes naturais propícios ao turismo de sol e praia.

Para o bom entendimento do trabalho proposto ressalta-se que 0 destino propicia diversos olhares, e o acompanhamento de outros professores, só enriquece o trabalho de aprendizagem. Principalmente quando os professores acompanhantes vêm de disciplinas das áreas humanas que somam entre si de modo interdisciplinar.

O processo metodológico consistiu, no primeiro momento, como pesquisa bibliográfica, onde buscamos a análise de legislação específica, projetos pedagógicos, Parâmetros Curriculares Nacionais, bem como de materiais que possam ter sido produzidos a respeito do tema. Já em sala de aula, o projeto da disciplina Visita Técnica II é apresentado e passa a ser construído em conjunto com os alunos, que recebem o roteiro com suas obrigações prévias e organizam-se em grupos, identificando de maneira participativa e através de pesquisas todos os ambientes que devem ser visitados, bem como os valores devidos para tal.

Por fim, a percepção da pesquisa dá-se através da observação e intervenção durante o processo de construção da visita técnica, durante sua execução e após o retorno, com a apresentação dos trabalhos (Figura 1). Para a pesquisa é um momento de observação, onde existiram entrevistas orais, momentos fotográficos, e a captação de diálogos informais.
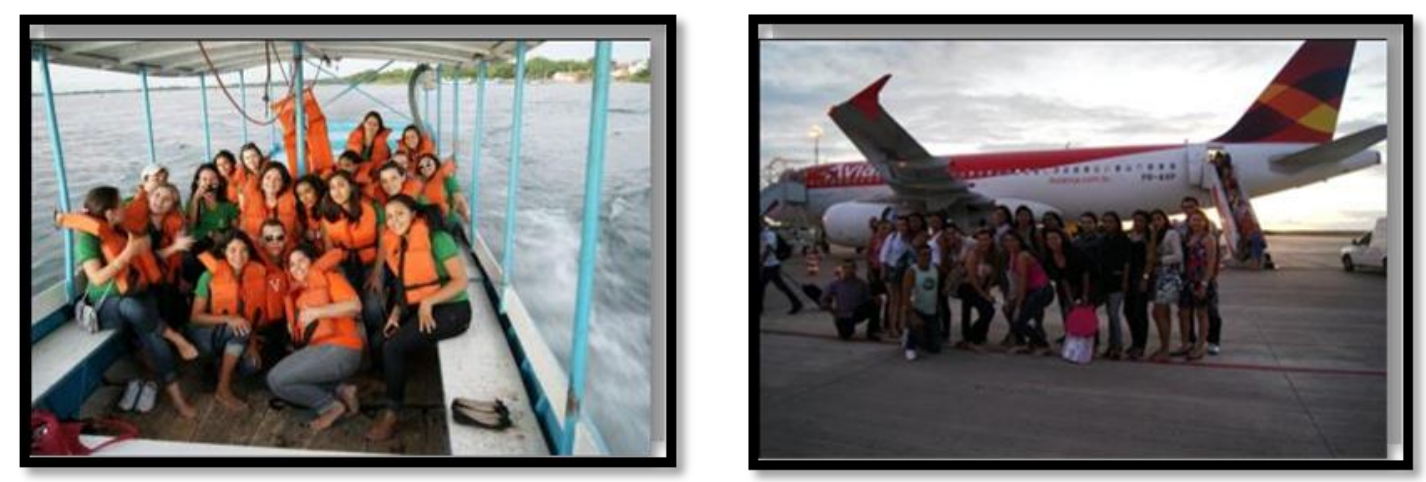

Figura 1: Visita Técnica Nacional - Pernambuco; Passeio em barco à llha do Rodeadouro Petrolina; Viagem aérea de Salvador à Petrolina

Figure 1: National Technical Visit - Pernambuco. Ride boat from Rodeadouro Island Petrolina; Air travel from Salvador to Petrolina.

\section{Proposta Pedagógica Integradora}

Aos Parâmetros Curriculares Nacionais (PCNs), elaborados pelo Ministério da Educação (BRASIL, 2001), foram adicionados os chamados temas transversais, permitindo que os professores trabalhassem diversos assuntos, através de novas formas de transmissão do conhecimento (atividades extraescolares, por exemplo).

É preciso atentar para o fato de que a possibilidade de inserção dos Temas Transversais nas diferentes áreas (Língua Portuguesa, Matemática, 
Ciências Naturais, História, Geografia, Arte e Educação Física) não é uniforme, uma vez que é preciso respeitar as singularidades tanto dos diferentes temas quanto das áreas. Existem afinidades maiores entre determinadas áreas e determinados temas, como é o caso de Ciências Naturais e Saúde ou entre História e Geografia, em que a transversalidade é fácil e claramente identificável.

Há que se considerar essas especificidades e o turismo pedagógico possibilita a vivência do alunado em diferentes áreas, mesmo que estas não sejam afins, posto que a proposta do mesmo (dessa atividade) é identificar em um meio (ambiente) a possibilidade de entendimento de diversas áreas do conhecimento, onde em uma viagem técnica podem-se visitar diversos ambientes em busca do alinhamento com o conteúdo transmitido em sala de aula, tais quais: praias, museus, área de proteção ambiental, ONGs, dentre outros.

Partindo do pressuposto de que o aluno deve ser o centro da construção do seu conhecimento, e que o papel do educador deve ser o de incentivá-los a construir o conhecimento para que, assim, sintam-se pertencentes a este meio onde vivem, seja ele local, regional, nacional ou internacional, o incentivo ao turismo pedagógico surge além de experiência gratificante, como ferramenta de aprendizagem para todos os que neste estejam envolvidos.

É importante salientar que o conhecimento precisa ser orientado através de um roteiro previamente elaborado, com o intuito de direcionar o conteúdo para uma melhor absorção pelos alunos, pois a prática por si só não se sustenta, e, se mal elaborado, pode, ao invés de produzir conhecimento, criarem-se dúvidas sobre as matérias abordadas.

Desta forma, e como proposta pedagógica integradora, elabora-se roteiro, no qual a construção das atividades se dá através de quatro etapas. Quais sejam:

1. Etapa: Construção da identidade e do foco do projeto - Esta etapa é necessária para que, através do alinhamento das ideias e questões principais sobre os conteúdos abordados em sala de aula, sejam definidas estratégias para a execução do projeto. Dá-se a partir de reuniões interdisciplinares com os professores das áreas que estarão envolvidas, para que se possam discutir temas que serão abordados e o foco de construção do aprendizado discente.

2a Etapa: Motivação através da coparticipação - Esta etapa está relacionada à apresentação do projeto aos alunos e distribuição das atividades em grupos para início da construção da busca pelas informações prévias e construção de material didático a ser utilizado durante as visitas programadas. Busca-se a coparticipação e envolvimento do aluno durante todo o processo, desde as pesquisas e escolha dos locais a serem visitados. Momento prévio do direcionamento da aprendizagem.

3a Etapa: Experimentação do conhecimento construído - Nesta fase, é dada ao aluno a oportunidade de perceber as questões anteriormente construídas, através da realização de excursão, visita técnica ou viagem. 0 
aluno desloca-se do seu ambiente rotineiro, a sala de aula, para vivenciar o aprendizado teórico, na prática. Esta prática pode se dar através da observação de documentos em museus ou laboratórios, coleta de material orgânico para análise e, posteriormente, entrevistas com gestores ou com a população do local visitado.

Mais especificamente, para o Curso de Guia de Turismo, os alunos vivenciam a hospedagem em hotéis, visita a Museus, viagens aéreas, alimentação em restaurantes, dentre outros serviços, em roteiros turísticos já consolidados no país.

4ª Etapa: Validação do conhecimento apreendido - Última fase do processo. De volta ao ambiente escolar, o aluno, através de práticas expositivas, discorrerá sobre os resultados do conhecimento apreendido, que podem ser apresentados através de relatórios, seminários, dramatizações, recursos audiovisuais ou portfólios. Neste momento, através da observação e intervenção, coletam-se os dados e informações sobre a visita. Este torna-se o momento das avaliações.

\section{Conclusão}

A pesquisa proposta surge por necessidade de resposta a questionamentos que afligem as pesquisadoras, quando se refere ao ensino de turismo, para grupos de alunos com compreensão limitada, quando diz respeito à educação formal, mas com uma bagagem de vida substancial. Percebe-se que o turismo é algo distante de uma população carente em tantos setores sociais como é o sertão do Piauí, onde a educação não é prioridade política e na maioria dos casos para eles mesmos, frente a necessidade de sobreviver antes de ler e escrever.

Desta forma, faz-se necessário utilizarmo-nos de ferramentas que possibilitem a absorção do conhecimento de maneira mais eficaz, e o turismo educativo, através de aulas-passeio ou visitas técnicas, demonstra potencial inquestionável em desempenho educacional.

Especificamente, buscamos analisar como os alunos do Curso Técnico em Guia de Turismo de São Raimundo Nonato, percebem o turismo pedagógico, através das visitas técnicas, como ferramenta de apreensão do conhecimento. Para o estudo das diversas áreas do turismo, é necessário que o aluno tenha ou possa vir a ter uma visão de mundo, visto que a disciplina direciona-se no sentido da globalização e padronização de serviços.

Através da observação dos alunos inseridos na pesquisa, percebeuse, desde o momento da construção do roteiro, em sala de aula, a mudança comportamental dos mesmos, e que foi se fortalecendo no decorrer da viagem, quando inseridos no cotidiano do turista e quando do encontro com os agentes receptores e prestadores de serviços turísticos nas localidades visitadas. Atividades pedagógicas, direcionadas ao desenvolvimento dos alunos, em atividades de entretenimento advindas das visitas, apropriadas das técnicas da atividade turística, através da roteirização das atividades, despertou nos alunos o sentimento prazeroso da aprendizagem. 
Diante desse perfil de alunado, o turismo pedagógico, surge como recurso de caráter interdisciplinar, rico no processo de transmissão do conhecimento e adaptável a qualquer nível de escolaridade. Entende-se que a eficácia das visitas ou viagens de estudo, quando inseridas em projetos pedagógicos e com roteiros previamente elaborados, faz com que a teoria repassada em sala de aula seja reconhecida e apreendida com maior facilidade, possibilitando uma compreensão aprofundada da cultura do local visitado.

\section{Referências Bibliográficas}

AB'SABER, A. A Natureza está ali, na esquina. Nova Escola. São Paulo. ed.139. p.40-42. Jan/fev. 2001.

ANDRADE, J. V. (2004) Turismo fundamentos e dimensões. (8. Ed). São Paulo: Afiliada.

ANSARAH, M. G. dos R. (2001). Teoria Geral do Turismo. In: ANSARAH, M. G. dos R. Paulo: SENAC. . (Org.). Turismo: como aprender como ensinar. São

BENI, M. C. (2002). Análise Estrutural do Turismo. (7 Ed). São Paulo: SENAC.

BRASIL. (1997). Secretaria de educação fundamental. Parâmetros Curriculares Nacionais: Temas transversais. Brasília: MEC/SEF.

CASTRO, M. D. R., MACHADO, M. M., VITORETTE, J. M. B. (2010). Educação Integrada e PROEJA: diálogos possíveis. Revista Educação e Realidade (v.35, n.1).

. PRESIDÊNCIA DA REPÚBLICA. Decreto $n^{\circ} 2.208$ de 17 de abril de

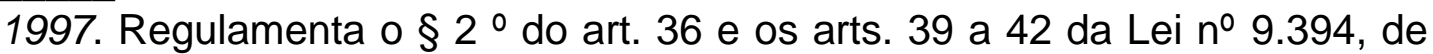
20 de dezembro de 1996, que estabelece as diretrizes e bases da educação nacional, e dá outras providências. Disponível em:<http://www.planalto.gov.br/ccivil_03/decreto/D2208.html>. Acesso em jun. 2015.

PRESIDÊNCIA DA REPÚBLICA. Decreto $n^{\circ} 5.154$ de 23 de julho de 2004. Regulamenta o $\S 2^{\circ}$ do art. 36 e os arts. 39 a 41 da Lei no 9.394, de 20 de dezembro de 1996, que estabelece as diretrizes e bases da educação nacional, e dá outras providências. Disponível em: <http://www.planalto.gov.br/ccivil_03/_ato2004-

2006/2004/Decreto/D5154.html>. Acesso em jun. 2015.

FREINET, Célestin. Pedagogia do bom senso. São Paulo, Martins Fontes, 1988;

GOMES, Marco Antônio de Oliveira \& COLARES, Maria Lilia Imbiriba Sousa. A educação em tempos de neoliberalismo: dilemas e possibilidades. Disponível em: http://periodicos.uem.br/ojs/index.php/ActaSciEduc/article/view/16978.

Acesso em: 30/07/2016; 
RUBIM, Ana Carolina Barroso. A prática do turismo pedagógico no contexto dos museus: a experiência de museus das cidades do Rio de Janeiro e Niterói. Niterói: UFF, 2010;

PERINOTTO, A. R. C. (2008). Turismo Pedagógico: uma ferramenta para educação ambiental. In: Caderno Virtual de Turismo.( v. 8, n. 1).

Flavia Oliveira da Silva Louzeiro: Instituto Federal de Educação, Ciência e Tecnologia do Piauí, Teresina, PI, Brasil.

E-mail: flavia.louzeiro@ifpi.edu.br

Link para o currículo Lattes: http://lattes.cnpq.br/1579504680053025

Data de submissão: 30 de agosto de 2016

Data de recebimento de correções: 17 de dezembro de 2018

Data do aceite: 17 de dezembro de 2018

Avaliado anonimamente 